\title{
Estimation of saturated hydraulic conductivity from ring infiltrometer test taking into account the surface moisture stain extension
}

\author{
Aurore Réfloch ${ }^{1,2 *}$, Jean-Paul Gaudet ${ }^{1}$, Laurent Oxarango ${ }^{1}$, Yvan Rossier ${ }^{1}$ \\ ${ }^{1}$ Université de Grenoble Alpes, CNRS, IRD, Grenoble INP, IGE, F-38000 Grenoble, France. \\ 2 Direction de l'Eau de la Métropole de Lyon - Le Triangle, 117 boulevard Marius Vivier Merle, 69003 Lyon, France. \\ * Corresponding author. E-mail: aurore.refloch@eaudugrandlyon.com
}

\begin{abstract}
A large single-ring infiltrometer test was performed in order to characterize the saturated hydraulic conductivity below an infiltration basin in the well field of Lyon (France). Two kinds of data are recorded during the experiment: the volume of water infiltrated over time and the extension of the moisture stain around the ring. Then numerical analysis was performed to determine the saturated hydraulic conductivity of the soil by calibration.

Considering an isotropic hydraulic conductivity, the saturated hydraulic conductivity of the alluvial deposits is estimated at $3.810^{-6} \mathrm{~m} \mathrm{~s}^{-1}$. However, with this assumption, we are not able to represent accurately the extension of the moisture stain around the ring. When anisotropy of hydraulic conductivity is introduced, experimental data and simulation results are in good agreement, both for the volume of water infiltrated over time and the extension of the moisture stain. The vertical saturated hydraulic conductivity in the anisotropic configuration is 4.75 times smaller than in the isotropic configuration $\left(8.010^{-7} \mathrm{~m} \mathrm{~s}^{-1}\right)$, and the horizontal saturated hydraulic conductivity is 125 times higher than the vertical saturated hydraulic conductivity $\left(1.010^{-4} \mathrm{~m} \mathrm{~s}^{-1}\right)$.
\end{abstract}

Keywords: Ring infiltrometer test; Infiltration basin; Numerical modeling; Saturated hydraulic conductivity; Anisotropy of hydraulic conductivity.

\section{INTRODUCTION}

Artificial recharge systems are used to increase or maintain aquifer water levels (Al-Muttair and Al-Turbak, 1991; Bouwer, 2002). In the well field for water supply of Lyon agglomeration (France), 12 infiltration basins are used to sustain the water table in times of peak demand for water and to prevent a possible contamination from the Rhône River by creating a hydraulic barrier and inverting the groundwater flow direction close to the pumping wells (Loizeau, 2013). Due to the high vulnerability and to ensure a better management of the water resources, it is important to characterize the groundwater flow below these infiltration basins (Bouwer, 2002; Dillon, 2005; Ostendorf et al., 2007). Several single-ring infiltrometer tests were performed to characterize hydraulic properties of the top soil layers. The main objective was to estimate representative values of the vertical saturated hydraulic conductivity to be used in a large scale groundwater flow model.

The analysis of infiltration tests should rigorously fall in the domain of parameter estimation and optimization methods. Several authors provided analysis of the parameter sensitivity for the Richards Equation (RE) for flow in the vadose zone (Babaeian et al., 2016; Mertens et al., 2005). Mertens et al., (2005) showed that the saturated hydraulic conductivity $\left(K_{s}\right)$ is generally one of the dominant parameters with the saturated moisture content $\left(\theta_{s}\right)$, and the van Genuchten parameters ( $\alpha$ and $n$ ). However, the single-ring infiltration test with a single imposed pressure head provides a relatively limited set of data (i.e. the volume of infiltrated water over time $\left(I_{t}\right)$ ) that could be insufficient to properly constrain the large number of parameters of the unsaturated hydraulic functions (Loizeau, 2013).

In this paper, one infiltration test is presented in order to highlight the potential misinterpretation of single-ring infiltrometer test if an isotropic homogeneous soil is considered. A measurement of the extension of the moisture stain around the ring $\left(r_{t}\right)$ is used as an additional information to improve the hydraulic conductivity estimation. The infiltrometer test was simulated using RE in an axisymmetric domain with the finite element software package Comsol Multiphysics 5.1. The proposed methodology also involved using experimental data to fix the value of initial, saturated and residual moisture contents. A simple trial and error approach is then used to estimate the optimal value of the vertical saturated hydraulic conductivity and permeability anisotropy. A sensitivity analysis is performed on van Genuchten parameters $\alpha$ and $n$.

\section{MATERIAL AND METHODS}

The single ring infiltrometer test

In the field, single-ring infiltrometer tests are usually conducted by small radius rings (White et al., 1992). In the study area, due to the spatial heterogeneity of the alluvial deposits and because of the coarse granulometry, as depicted in Fig. 1, a large single-ring infiltrometer was used (of $1 \mathrm{~m}$ in diameter). In this paper we focus on a unique single-ring infiltrometer test, realized in one infiltration basin of the well field of Lyon (France). This infiltrometer test was realized after the stripping of the sand layer (which is added at the bottom of the basin to filter mineral and biotic particles which are present in the water), in order to estimate the saturated hydraulic conductivity of the alluvial deposits below the sand layer.

The ring was pushed about $0.01 \mathrm{~m}$ into the soil to limit the impact on infiltration flow direction (Dusek et al., 2009). To prevent water leakage from the edges of the ring, bentonite was added to seal the ring on the soil. A mean hydraulic head of $0.07 \mathrm{~m}$ was imposed in the ring: 14 cycles of $0.02 \mathrm{~m}$ of magnitude (between 0.06 and $0.08 \mathrm{~m}$ ) were performed during the total duration of the experiment ( 7.5 hours). The volume of added water over time in the ring was measured using a single jet turbine water meter (ITRON Aquadis, precision: $0.01 \mathrm{~L}$ ). The volume of infiltrated water over time, $I_{t}\left[\mathrm{~L}^{3}\right]$, was measured with the evolution of hydraulic head in the ring over time 

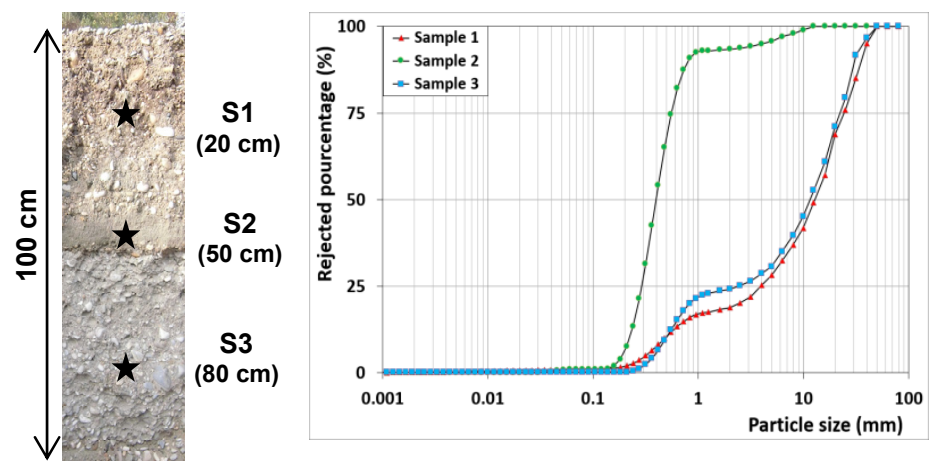

Fig. 1. Example of a pedological pit with locations for samplings and particle size analysis of three alluvial samples.

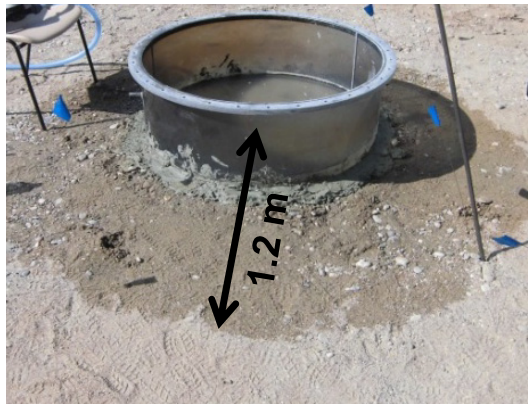

Fig. 2. Visual measurement of the moisture stain extension (from the center of the ring to the front of the stain) at $t=2$ hours.

(between time step of 970 and 2160 seconds). In parallel, the extension of the moisture stain around the ring, $r_{t}[\mathrm{~L}]$, was visually measured (Fig. 2) on a scale in centimeters according to four directions around the ring. These observations were then averaged to take into account the possible effects of topography which could influence the spatial extension of the stain.

The volumetric moisture content was evaluated by means of undisturbed ring samples $(7.4 \mathrm{~cm}$ in diameter, $5 \mathrm{~cm}$ height). The residual moisture content $\left(\theta_{r}\right)$ value is the average of 5 measurements, done in very dry conditions before the experiment, on undisturbed soil samples: $\theta_{r}=0.01 \mathrm{~m}^{3} \mathrm{~m}^{-3}$ (standard deviation $\sigma=0.0020$ ). The water content in the center of the ring at the end of the experiment is considered equal to the saturated water content $\left(\theta_{s}\right)$. The $\theta_{s}$ value is the average of measurements on 2 undisturbed soil samples: $\theta_{s}=0.25 \mathrm{~m}^{3} \mathrm{~m}^{-3}$ $(\sigma=0.0015)$. In order to compare experimental data and computed results of $r_{t}$, we use the value of $\theta=0.15 \mathrm{~m}^{3} \mathrm{~m}^{-3}$ for identifying the wetting front position in simulations. This value was estimated using measurements on 4 soil samples $(\sigma=0.0260)$.

To better know the lithology of alluvial deposits below the basin, several pedological pits were dug in the infiltration basin (to a depth of $1.5 \mathrm{~m}$ ). These pits highlighted the spatial heterogeneity of alluvial deposits with some gravel, sand, mixed gravel/sand layers, as illustrated on Fig. 1. Concerning the grain size volumetric proportions of particles $<1600 \mu \mathrm{m}$ (measured by laser diffractometry Malvern Mastersize $2000 \mathrm{G}$ ), sands are largely dominant (more than 90\%). Based on ISO 146882:2004, the study area soil is considered as a sand or a coarsesand.

An important visual observation was made on all pedological pits: a compacted layer of about $0.3 \mathrm{~m}$ was found at the top. In this layer, we found $80.2 \%$ of gravel, $19.2 \%$ of sand and $0.6 \%$ of silt and clay (sample 1 on Fig. 1).

\section{Numerical modeling}

Numerical modeling was realized with the finite element software package Comsol Multiphysics 5.1, to estimate the saturated hydraulic conductivity $K_{s}$ of the soil by calibration. Water flow and variations of water content are modeled with the Richards equation (Richards, 1931), in a 2D axisymmetric domain:

$\frac{\partial \theta}{\partial t}=\frac{1}{r} \frac{\partial}{\partial r}\left[K_{s h} * K_{r}(h) \frac{\partial H}{\partial r}\right]+\frac{\partial}{\partial z}\left[K_{s v} * K_{r}(h) \frac{\partial H}{\partial z}\right]$

with $H=h+z$

where $K_{s h}\left[\mathrm{~L} \mathrm{~T}^{-1}\right]$ and $K_{s v}\left[\mathrm{~L} \mathrm{~T}^{-1}\right]$ are respectively the horizontal and vertical saturated hydraulic conductivities, $K_{r}(h)[-]$ is the relative hydraulic conductivity function, $H[\mathrm{~L}]$ is the hydraulic head, $h[\mathrm{~L}]$ is the pressure head, $z[\mathrm{~L}]$ is the vertical coordinate, $r[\mathrm{~L}]$ is the radial coordinate, $\theta\left[\mathrm{L}^{3} \mathrm{~L}^{-3}\right]$ is the water content and $t[\mathrm{~T}]$ is the time.

Water retention curve $\mathrm{Se}(\mathrm{h})$ and hydraulic conductivity evolution $K(\mathrm{~h})$ are described by the van Genuchten - Mualem functions (Mualem, 1976; van Genuchten, 1980).

$$
\begin{aligned}
& \operatorname{Se}(h)=\frac{\left(\theta-\theta_{r}\right)}{\left(\theta_{S}-\theta_{r}\right)}=\left[1+(\alpha h)^{n}\right]^{-m} \\
& K_{r}(h)=S e^{0.5}\left[1-\left(1-S e^{\frac{1}{m}}\right)^{m}\right]^{2} \text { with } m=1-(1 / \mathrm{n})
\end{aligned}
$$

where $S e[-]$ is the effective saturation, $\theta_{r}\left[\mathrm{~L}^{3} \mathrm{~L}^{-3}\right]$ is the residual water content, $\theta_{s}\left[\mathrm{~L}^{3} \mathrm{~L}^{-3}\right]$ is the saturated water content, $\alpha\left[\mathrm{L}^{-1}\right]$, and $\mathrm{n}[-]$ are the van Genuchten's parameters.

\section{Single-ring configurations}

Two simulation configurations were considered: an isotropic one (i.e. the hydraulic conductivity is defined at any particular location and time by a single scalar value: $K_{s h}=K_{s v}$ in Eq. 1) and an anisotropic one $\left(K_{s h} \neq K_{s v}\right.$ in Eq. 1). Values of isotropic and anisotropic soil saturated hydraulic conductivities are reported in Table 1. In both cases, van Genuchten's water retention curve parameters $\alpha$ and n (van Genuchten, 1980) are fixed to $2 \mathrm{~m}^{-1}$ and 2.4 , respectively. Values of $\alpha$ and $\mathrm{n}$ have been determined in a previous study by a sensitivity analysis (Loizeau, 2013). In our study, the focus was not on the precise determination of van Genuchten parameters that are important for transient water flow regimes. Here, we focus on infiltrations at long times close to the saturated water content, where the most important parameter is the saturated hydraulic conductivity.

The 2D axisymmetric computation domain is $2 \mathrm{~m}$ deep and $2.5 \mathrm{~m}$ wide (Fig. 3). These dimensions were chosen to ensure no 


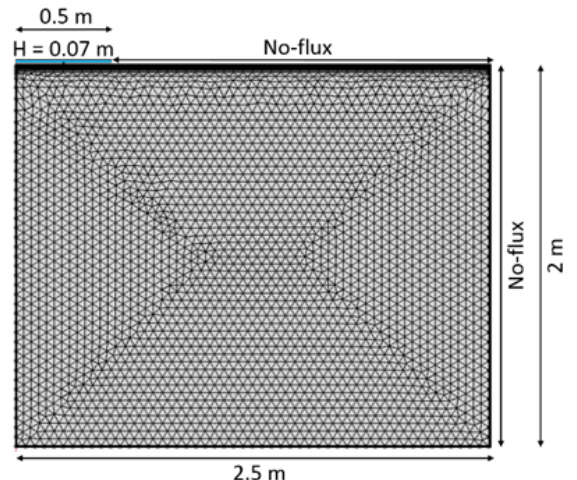

Fig. 3. Geometry of the domain and boundaries conditions.

influence of the boundaries on the flow field. Hydrostatic equilibrium was defined as the initial condition with a constant hydraulic head of $-0.5 \mathrm{~m}$ at the bottom of the computation domain. A constant hydraulic head of $0.07 \mathrm{~m}$ was imposed in the ring (of $0.5 \mathrm{~m}$ radius). No flow condition was imposed in all the other boundaries.

\section{Calibration of hydraulic parameters}

Simulations were fitted by trial and errors on experimental data $\left(I_{t}\right.$ and $\left.r_{t}\right)$ to estimate $K_{s}$ in the isotropic domain and $K_{s h}$, $K_{s v}$ in the anisotropic domain. For this last case, 12 additional simulations have been performed by varying $K_{s h}$ and $K_{s v}$ (in the range of $\pm 20 \%$ ) around its optimal values. Calculations of root mean square error (RMSE) were done to compare the experimental and numerical data sets in order to estimate the fit quality and exhibit the sensitivity of the model around the optimal values (Willmott, 1981).

\section{RESULTS AND DISCUSSION Single-ring infiltrometer test}

Fig. 4 shows that at the end of the experiment, about $0.21 \mathrm{~m}^{3}$ of water was infiltrated in the soil and the moisture stain reach $1.75 \mathrm{~m}$ from the center of the ring.

\section{Single-ring simulation}

According to the single-ring isotropic domain, $K_{s}$ of the soil is estimated at $3.810^{-6} \mathrm{~m} \mathrm{~s}^{-1}$. Considering the set of cumulative infiltration volume $I_{t}$, the model provides a very satisfying agreement with a RMSE of 0.00347 . However, as depicted on Fig. 4, this simple model is not able to represent accurately the moisture stain extension measured during the experiment $(\mathrm{RMSE}=0.66423)$. It was therefore necessary to add complexity in the model by taking into account an anisotropy of hydraulic conductivity. This single-ring anisotropic domain simulation shows that experimental data and simulation results are in good agreement both for $I_{t}$ and $r_{t}$. In this simulation, $K_{s v}$ is estimated at $8.010^{-7} \mathrm{~m} \mathrm{~s}^{-1}$ and $K_{s h}$ at $1.010^{-4} \mathrm{~m} \mathrm{~s}^{-1}$. Horizontal saturated hydraulic conductivity, $K_{s h}$, is 125 times higher than $K_{s v}$ and $K_{s v}$ is 4.75 times smaller than $K_{s}$ in the isotropic domain. Fig. 5 shows that a clear minimum is exhibited on the control data set for $I_{t}$ with a minimum RMSE of 0.0039 (Fig. 5a and b). Concerning the control data set for $r_{t}$, it proved less sensitive to the vertical hydraulic conductivity $K_{s v}$ (Fig. 5.d) but allows to validate satisfyingly the optimal horizontal hydraulic conductivity $K_{s h}$ (Fig. 5.c). A larger error is observed on $r_{t}$ with a minimum RMSE of 0.0637 which may be due to the lake of accuracy of the moisture stain extension measurement. After the fitting procedure, additional simulations have shown that decreasing $\alpha$ down to $1.8 \mathrm{~m}^{-1}$ leads to overestimate $I_{t}$ and increasing $\alpha$ up to $2.2 \mathrm{~m}^{-1}$ leads to underestimate $I_{t}$. These additional simulations had shown also that decreasing $\mathrm{n}$ down to 2.2 leads to underestimate $I_{t}$ and increasing n up to 2.6 leads to overestimate $I_{t}$.

At the end of the simulation ( $t=7.5$ hours $)$, the water content distributions differ greatly between isotropic and anisotropic domain results as illustrated in Fig. 6. The infiltration front is limited to a depth of $0.25 \mathrm{~m}$ in the anisotropic case. When compared to the pedological pits observations (Fig. 1), only the top compacted layer appears to be wetted. The deeper soil layers were probably not affected by the infiltration. This experiment is thus probably not suitable to characterize a multilayers domain.

\section{SUMMARY AND FUTURE PROSPECTS}

A large single-ring infiltrometer test was adapted for the study area because of the coarse granulometry of alluvial deposits, the spatial heterogeneity and the anisotropy of hydraulic conductivity. Single-ring numerical analysis allows to determine $K_{s h}$ and $K_{s v}$, after fitting the simulation with $I_{t}$ and $r_{t}$. Numerical modeling of such an infiltration test should be constrained by field measurements $\left(\theta_{s}, \theta_{r}, r_{t}\right)$ to limit the number of unknown parameters. Even if the fitting of the model could be

Table 1. Soil hydraulic properties for isotropic and anisotropic configurations.

\begin{tabular}{|c|c|c|c|c|c|c|}
\hline & $\theta r\left[\mathrm{~m}^{3} \cdot \mathrm{m}^{-3}\right]$ & $\theta s\left[\mathrm{~m}^{3} \cdot \mathrm{m}^{-3}\right]$ & $\alpha\left[\mathrm{m}^{-1}\right]$ & $n[-]$ & $K s_{h}\left[\mathrm{~m} . \mathrm{s}^{-1}\right]$ & $K s_{v}\left[\mathrm{~m} \cdot \mathrm{s}^{-1}\right]$ \\
\hline Isotropic model & 0.01 & 0.25 & 2 & 2.4 & $3.810^{-6}$ & $3.810^{-6}$ \\
\hline Anisotropic model & 0.01 & 0.25 & 2 & 2.4 & $1.010^{-4}$ & $8.010^{-7}$ \\
\hline
\end{tabular}
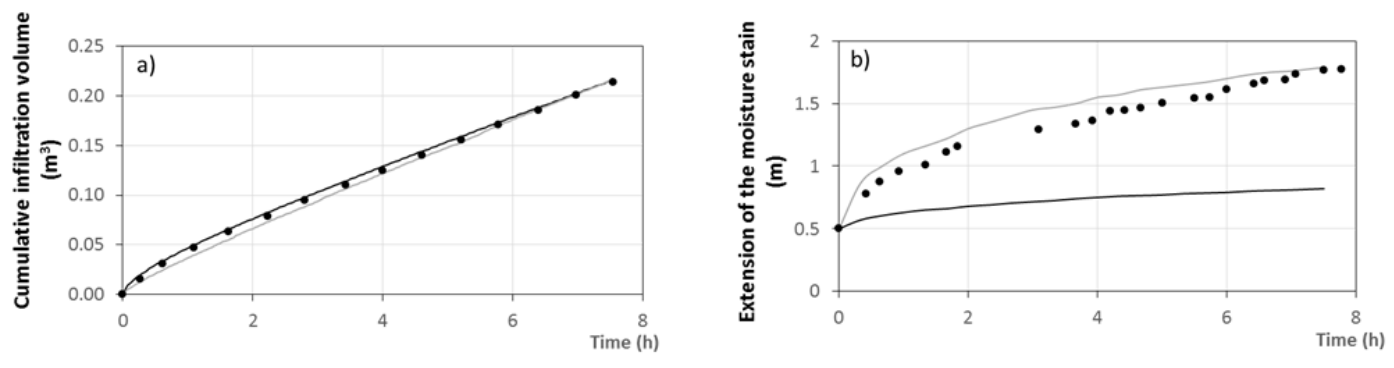

- Experimental data - Isotropic domain - Anisotropic domain

Fig. 4. Comparison between experimental data and numerical results (for isotropic and anisotropic configurations) a) cumulative infiltration volume, $b$ ) extension of the moisture stain. 


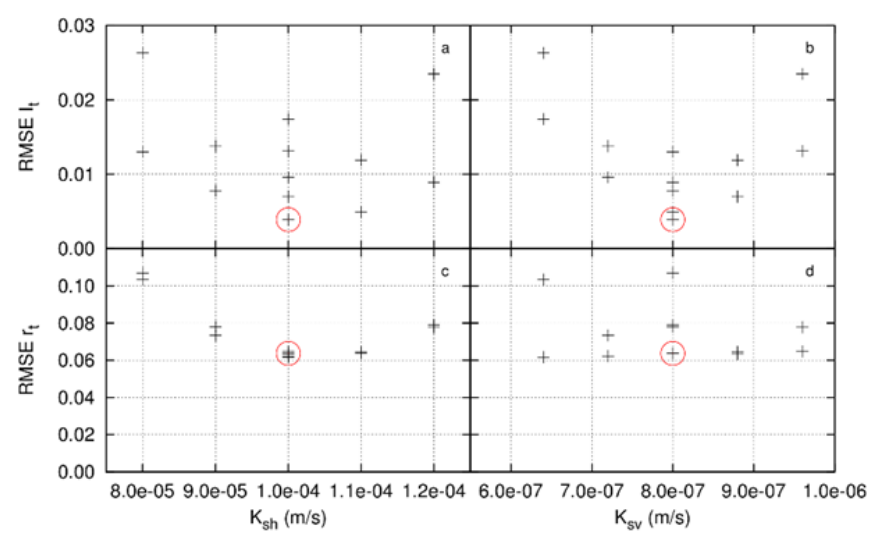

Fig. 5. Results of RMSE (root mean square error) calculations between experimental data and simulation, for $I_{t}$ and $r_{t}$. The red circle corresponds to the optimal $K_{s h}$ and $K_{s v}$ values of the anisotropic model.

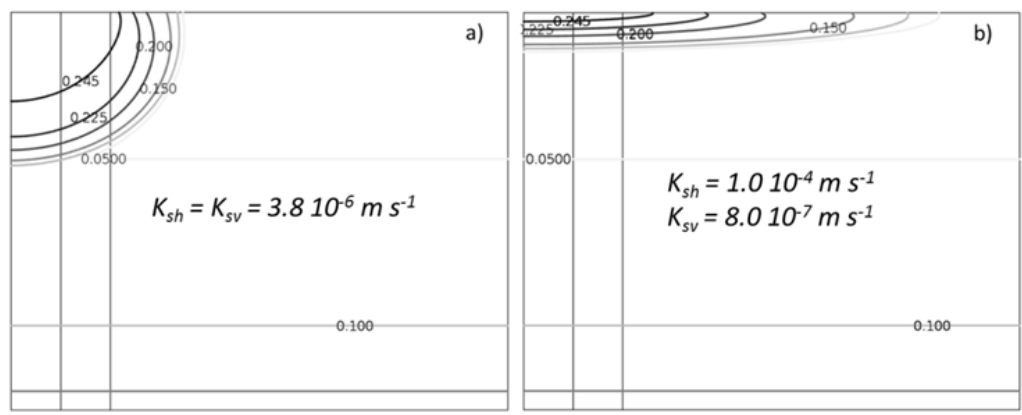

Fig. 6. Distribution of water content at the end of the simulation ( $t=7.5$ hours) for a) isotropic and $b)$ anisotropic configurations.

achieved with only $I_{t}$, the anisotropy of hydraulic conductivity had to be included in the numerical model in order to account for the time evolution of $r_{t}$. The anisotropy of hydraulic conductivity in the soil could be due to the stratified nature of alluvial deposits or/and the soil compaction during the construction of the infiltration basin. The result of the modeling shows an anisotropy ratio of 125 between horizontal and vertical hydraulic conductivity in the compacted layer. The single-ring numerical analysis corresponds to the minimal methodology to be operated to obtain reliable results (with initial condition, boundaries conditions, fitting results on $I_{t}$ and $r_{t}$, anisotropy of hydraulic conductivity).

The proposed modeling is also a tool of better understanding the functioning of the field, and could be improved by performing a finer mapping of the water content at the end of the experiment, and thermal or chemical tracing.

Acknowledgements. The authors wish to thanks ANRT (French national association for research and technology) and the Grand Lyon urban community for supporting this research.

\section{REFERENCES}

Al-Muttair, F.F., Al-Turbak, A.S., 1991. Modeling of infiltration from an artificial recharge basin with a decreasing ponded depth. J. King Saud Univ. Eng. Sci., 3, 89-100.

Babaeian, E., Homaee, M., Montzka, C., Vereecken, H., Norouzi, A.A., van Genuchten, M.T., 2016. Soil moisture prediction of bare soil profiles using diffuse spectral reflectance information and vadose zone flow modeling. Remote Sensing of Environnement, 187, 218-229.

Bouwer, H., 2002. Artificial recharge of groundwater: hydrogeology and engineering. Hydrogeology Journal, 10, 121-142. DOI: 10.1007/s10040-001-0182-4.
Dillon, P., 2005. Future management of aquifer recharge. Hydrogeology Journal, 13, 1, 313-316. DOI: 10.1007/s10040-0040413-6.

Dusek, J., Dohnal, M., Vogel, T., 2009. Numerical analysis of ponded infiltration experiment under different experimental conditions. Soil and Water Research, 4, S22-S27.

ISO 14688-2:2004. Reconnaissance et essais géotechniques Dénomination, description, classification des sols.

Loizeau, S., 2013. Amélioration de la compréhension des fonctionnements hydrodynamiques du champ captant de CrépieuxCharmy. Thèse à l'Université de Grenoble, $220 \mathrm{p}$.

Mertens, J., Madsen, H., Kristensen, M., Jacques, D., Feyen, J., 2005. Sensitivity of soil parameters in unsaturated zone modeling and the relation between effective, laboratory and in situ estimates. Hydrol. Process., 19, 1611-1633.

Mualem, Y., 1976. A new model for predicting the hydraulic conductivity of unsaturated porous media. Water Resour. Res., 12, 513-522.

Ostendorf, D.W., DeGroot, D.J., Hinlein, E.S., 2007. Unconfined aquifer response to infiltration basins shallow pump tests. Journal of Hydrology, 338, 132-144.

Richards, L.A., 1931. Capillary conduction of liquids through porous mediums. Physics, 1, 318-333.

van Genuchten, M.T., 1980. A closed-form equation for predicting the hydraulic conductivity of unsaturated soils. Soils Sci. Soc. Am. J., 44, 892-898.

White, I., Sully, M.J., Perroux, K.M., 1992. Measurement of surface-soil hydraulic properties. Disk permeameters, tension infiltrometers and other techniques. In: Topp, C.G., Reynolds, W.D., Green, R.E. (Eds.): Advances in Measurement of Soil Physical Properties: Bringing Theory into Practice. Soil Sci. Soc. Am., Madison, WI.

Willmott, C.J., 1981. On the validation of models. Physical Geography, 2, 184-194. 